\title{
Analyzing of Relationship between Organizational Citizenship Behavior and Performance of Pasargad Insurance Employees in Mazandaran Province
}

\author{
Reza Abedzadeh Ledari ${ }^{1 *}$, Behjat Sazgar ${ }^{2}$ \\ $1 *$ Department of Business Management ,Faculty of Management, \\ Babol Branch, Islamic Azad University, Babol ,Iran. \\ Email : reza.abedzadeh@gmail.com \\ ${ }^{2}$ Department of Business Management, Faculty of Management, \\ Babol Branch, Islamic Azad University,Babol ,Iran
}

\begin{abstract}
The present study was an attempt to analyze the relationship between organizational citizenship behavior and the performance of Pasargad Insurance employees in Mazandaran province. The research type is descriptive-survey. The statistical population of the study included 50 employees of Pasargad Insurance Company in Mazandaran province, which 44 of them were selected as the sample size using a convenience sampling method. The research tools included Organ and Kanowski Organizational Citizenship Behavior Questionnaire (1996) and the researcher-made employee performance questionnaire. The reliability of the questionnaires was calculated at 0.763 and 0.817 , respectively using Cronbach's alpha coefficient. Face and content validities were used to determine the validity of these tools. To analyze the data, the normality of the data distribution was first examined using Kolmogorov-Smirnov test and then the significance of the hypothesis was assessed using Pearson correlation coefficient tests. The results revealed a relationship between organizational citizenship behaviors and employees' performance. There was also a relationship between the components of altruism, conscientiousness, sportsmanship, civic virtue and courtesy and performance.
\end{abstract}

Keywords: Organizational Citizenship Behavior, Performance, Pasargad Insurance Company, Mazandaran Province

\section{Introduction}

In the current highly competitive world, organizations are constantly looking for new ways to maximize the performance and effort of their employees. In spite of increasing use of information technology, there is still a gap in the organization efficiency. It is now strongly believed that an organization's efficiency depends to a large extent on the efforts of employees that go beyond defined requirements. In recent years, the development of new technologies and the growing global economy have resulted in increasing competition and rapid changes in the nature of work, organizations and their employees. As a result of these changes and in line with preparing for future changes, increasing pressure is imposed on employees to take responsibility for career promotion planning, training, and salaries and fees. To compete in the global arena, organizations also tend to meet customer needs and expectations and adapt to the changing nature of jobs, and try to select employees who go beyond the assigned role. Bateman \& Organ (1983) first coined the term organizational citizenship behavior and defined it as follows: a personal behavior that is voluntary and it is not explicitly or implicitly aroused by a formal reward system and will increase organizational efficiency. Also, it is tendency of employees to perform behaviors that go beyond the formal requirements of their role and position and it is recognized as one of the main components of organizational citizenship behavior. Thus, organizational citizenship behavior can be considered "lubricating the movement of social machine of organization." Katzukan (1978) considered it as a role beyond the behaviors that increases organizational efficiency. In 1930, Chester I. Barnard referred to the phenomenon of ERB or extra-role behaviors and defined it as spontaneous behaviors, which include both the roles specified in job description and expected and accepted behavior of the organization management and extra-role behaviors that are manifestations of help to new employees in organizations and lack of violating the rights of others and expressing intimacy with others and accepted by the management of the organization and also includes trans-role behaviors (Sanoobari, 2008, p. 82).

A good organizational citizen is a thought and idea and includes various behaviors of employees such as accepting and undertaking additional duties and responsibilities, following the rules and procedures of the organization, maintaining and developing a positive attitude, patience and tolerance of dissatisfaction and problems at work (Zarei Matin and Jandaghi, 2006, p. 35). In general, citizenship behavior is a valuable and useful behavior that people express voluntarily (Eslami and Sayar, 2007). In organizational citizenship behavior, those behaviors are generally considered that performing them is not obligatory on the part of the organization, but their performing 
by employees cause benefit for organization. (Kwantes, 2003, p. 5). Organizational citizenship behavior increases the productivity of employees and workgroups, encourages teamwork, increases communication and collaboration between employees, reduces error rates, and increases employees' involvement in organizational issues, and improves morale, increases organizational commitment and job satisfaction, reduces turnover intentions, reduces absenteeism, and destructive job behaviors. Also, by improving the external factors such as customer satisfaction, service quality and customer loyalty; it leads to excellent quality in job performance. Thus, given the positive and direct effect of organizational citizenship behavior on the quality of services provided and consequently on the profitability of the organization, paying attention to such behaviors can be one of the ways to increase the organizations' efficiency and less attention has been paid to this issue. Thus, the present study aims at investigating the organizational citizenship behavior and its effect on the creation of extra-role activities in Pasargad Insurance in Mazandaran province. Before taking any step concerning organizational citizenship behaviors, one should answer the question of what is the relationship between organizational citizenship and organizational performance. Hence, the present study aimed at identifying and investigating organizational citizenship behaviors affecting employee performance and examining the relationship between these behaviors and employee performance in the studied population to identify and improve organizational citizenship behaviors in line with the organizational goals.

\section{Theoretical foundations of research}

\section{Organizational citizenship behavior}

The concept of organizational citizenship behavior was first introduced to the world of science by Bateman and Organ in the early 1980s. Early studies on organizational citizenship behavior focused more on identifying the responsibilities or behaviors of employees in the organization and employees in the organizations were often overlooked.

Although these behaviors were incompletely measured or even sometimes overlooked in traditional job assessments, they were effective in improving organizational effectiveness. These actions taking place at workplace are defined as follows:

"A set of voluntary behaviors that are not part of one's formal duties, but are performed by him or her and effectively improve the tasks and roles of the organization" (Apple Bam et al., 2004). For example, a worker may not need to work overtime and stay at work late, but still stays longer than his or her formal working hours to improve current affairs and facilitate the organization's workflow and help others. Organ also believes that organizational citizenship behavior is an individual and voluntary behavior that is not directly designed by formal reward systems in the organization, but promotes the effectiveness and efficiency of organization. This definition emphasizes three main characteristics of citizenship behavior: first, that this behavior must be voluntary, i.e. it is neither a predetermined duty nor part of the formal or official duties of the person. Second, the benefits of this behavior have an organizational aspect. Third, organizational citizenship behavior has a multidimensional nature. Based on these definitions, a person as an organizational citizen is expected to serve the goals of the organization more than the requirements of his or her role and beyond his or her formal duties. In other words, the structure of organizational citizenship behavior seeks to identify, manage and evaluate extra-role of employees who work in the organization and as a result of these behaviors; organizational effectiveness is improved (Eslami and Sayar, 2007).

Key elements in defining organizational citizenship behavior are:

1- A type of behavior that goes beyond what is formally defined by the organization.

2- A type of unspecified behavior.

3- Behaviors that are not specifically rewarded and are not identified by the formal structures of the organization.

4- Behaviors that are crucial for the performance, effectiveness and success of the organization's operations (Aree, 2009).

\section{Organizational citizenship behavior outcomes}

Organizational citizenship behavior increases productivity of employees and workgroups, communication, collaboration among employees, encourages teamwork, reduces the rate of errors, and increases employees' involvement in organizational issues, and generally provides a good atmosphere. By influencing factors within the organization such as organizational climate, improving morale, increasing organizational commitment, job satisfaction, reducing turnover intentions, reducing absenteeism and destructive job behaviors and also by influencing the improvement of external factors such as job satisfaction, quality of service and customer loyalty, organizational citizenship behavior increases the quality of employees' performance (Castro et al., 2004).

The effect of organizational citizenship behavior on performance

Based on Karam Baya (1989), employees working in organizational units with high performance and efficiency are more concerned with citizenship behaviors. Some researchers have referred to effects of citizenship behavior on organizational performance, including the following cases: 
1- Organizational citizenship behavior increases the efficiency of co-workers. Helping behaviors are helpful in disseminating experiences and skills among members of the group or work units.

2- Organizational citizenship behavior increases the efficiency of managers. Chivalrous employees free the manager from time to get involved in trivial problems.

3- Citizenship behavior frees resources and facilities to spend on more effective goals. When employees help each other with work problems, there is no need for manager's help, and as a result, the manager spends more time on more important issues. If employees increase their job ability through their growth activities, they will perform their duties more skillfully.

4- Helping behaviors improve group ethics and cohesion and create a sense of belonging among group members, resulting in attracting and retaining the best employees (Saemi and Mahmoudi, 2009, p. 8).

\section{Necessity of performance assessment}

Since improving the performance of executive bodies creates a potential force that supports many growth opportunities, governments and organizations are making great efforts in this regard. Performance assessment can raise awareness of progress in improving performance; as a result, it provides adequate motivation and opportunity to improve the quality of performance of organizations. Performance assessment also stimulates sense of curiosity, questioning and challenges about the way of doing things and the way of allocating the resources. Thus, performance assessment and measurement makes the system intelligent and motivates people to behave optimally. Given what was stated above, performance assessment can provide the necessary feedback in the following cases:

- The level of successfully implementation of the formulated policies,

- The extent to which policies are formulated correctly,

- Providing indicators for organizational growth,

- Obtaining information about the current situation of organization,

- Identifying potential for improvement in the performance of organization,

- The efficiency and effectiveness of programs and activities,

- Ensuring a continuous process of performance improvement,

- Identifying problems, opportunities and limitations,

- Future vision and direction of the programs in the national and international space,

- Way of allocating resources and facilities and human resources and the level of employee's involvement in implementation of approved programs,

-Level of accountability or responsibility.

The use of performance assessment systems and methods also brings three key benefits to organizations:

1- Determining the strategy and long-term goals of the organization

3- Providing information to respond to stakeholders

3- Emphasis on public involvement of employees in the organization (Bani Fatemi, 2007, p. 43).

\section{Research literature}

In an article entitled "Investigating the relationship between organizational citizenship behavior and employee performance", Musa Khani et al (2012) examined the relationship between organizational citizenship behaviors and performance of employees in Zanjan Governorate with the aim of improving the employees' performance and examining the citizenship behaviors that are effective in improving the employees' performance in 2009. Their research developed some hypotheses in this regard. It was a descriptive-correlational research and it is applied in terms of objective and a survey method in terms of collecting data. In this regard, Zanjan Governorate employees consisting of 4 deputies were selected as statistical population and a 22-item questionnaire based on the Likert scale was used to assess the variables of organizational citizenship behaviors and annual assessment scores were used to assess employees' performance. After examining the validity of the questionnaire, Cronbach's alpha method was used to calculate the reliability $(\alpha=85 \%)$. Correlation, regression and path analysis tests were used to perform statistical calculations. Finally, the results of SPSS software showed that all confirmed research hypotheses were confirmed and the variable of organizational citizenship behaviors had a direct and significant relationship with employees' performance. Scout Bonab et al (2013) evaluated the relationship between organizational citizenship behavior and employees' performance. In the mentioned study, the relationship between organizational citizenship behaviors and employees' performance in Bonab Islamic Azad University with the aim of improving employees' performance with respect to organizational citizenship behaviors was evaluated. The studied variables of organizational citizenship behaviors included: 1- altruism 2- conscientiousness 3sportsmanship 4-civic attitude 5-respect. Given the objective of the research, secondary objectives and hypotheses of study were formulated. This research was an analytical research conducted by correlation method and survey 
method was used to collect data. In this regard, employees of Bonab Azad University were selected as a statistical population and 22-item and 21-item questionnaires (both based on the Likert scale) were used to assess the variables of organizational citizenship behaviors and employees' performance, respectively. After examining the validity of the questionnaires, Cronbach's alpha method was used to calculate their reliability. After determining the sample size, 222 questionnaires were distributed to assess the variables of citizenship behaviors and performance. SPSS and EXCEL software and correlation, regression and chi-square tests were used to perform the calculations. Finally, the results revealed a significant relationship between organizational citizenship behaviors and employees' performance. Also, the significant relationship between each of the defined components of organizational citizenship behavior and employees' performance was also investigated and confirmed.

In a study entitled the relationship between organizational citizenship behavior and organizational performance of Fasa medical staffs, Sadegh and Arabzadeh (2011) examined the relationship between organizational citizenship behavior and organizational performance among Fasa medical staffs. The statistical population of the mentioned correlational study included the medical staffs of Fasa, which consisted of 212 people. Using Morgan table, 136 of theme, including 77 female and 59 male people, were selected as statistical sample. It should be noted that the stratified random sampling method was used.

In the mentioned study, Organ and Konowski Organizational Citizenship Behavior Questionnaire (1996) Lutans et al Organizational Performance Questionnaire (1999) were used. The results of examining the relationship between organizational citizenship behavior and organizational performance showed a significant relationship between organizational citizenship behavior and organizational performance among Fasa medical staffs. The results of examining the relationship between the components of citizenship behavior and performance also showed that among the components of organizational citizenship behavior, only conscience has no significant relationship with organizational performance, while other components showed a significant relationship with organizational performance. Also, investigating the components of citizenship behavior showed that the components of organizational citizenship behavior can predict organizational performance and among these components, altruism is the strongest predictor and conscience is the weakest predictor. Finally, the research question showed that citizenship behavior is significantly different between males and females. In his study entitled "The relationship between organizational citizenship behavior and organizational performance in a financial institution in Taiwan", Cheng-Chen Lin concluded that organizational citizenship behavior has a positive effect on organizational performance. However, the study showed that teamwork plays a mediator role in direct impact of organizational citizenship behavior on individual and group performance. In another study conducted by Hee Yoon in 2003, the relationship between organizational citizenship behavior and service quality was examined. The researchers first hypothesized "the positive relationship between job satisfaction and trust and some aspects of organizational citizenship behavior (altruism, civic virtue and sportsmanship), and then, using the SERVQUAL index to measure service quality, they showed a relationship between citizenship behavior and quality of service. They examined 95 service companies and surveyed 567 customers to assess the quality of service. In different stages of research, a sample of 201 service employees in different age groups was investigated. The most important hypothesis of this study was that "customers' perception of quality of service is positively associated with altruism, civic virtue and sportsmanship and organizational citizenship behavior.

\section{Methods}

The present study is an applied research in terms of objective and survey-correlational-descriptive in terms of research method. The statistical population of this study includes all employees of the administrative department of Pasargad Insurance Company in Mazandaran province in Babol, Sari, Behshahr, Amol, Chalous and Tonekabon cities. Total number of employees was 50 people. Using a convenience random sampling method, the required number of elements was selected and using Morgan table, among 50 people as population of study, 44 were selected as the sample size.

Data collection tools

In the present, library studies and field methods were used to collect data.

\section{Questionnaires}

A- Organ and Kanowski Organizational Citizenship Behavior Questionnaire (1996)

This questionnaire consists of 15 questions.

Altruism: questions 1 to 3 of the questionnaire

Conscientiousness: Questions 4 to 6 of the questionnaire

Sportsmanship: questions 7 to 10 questionnaires

Civic Virtue: Questions 11 to 13 of the questionnaire

Courtesy: Questions 14 to 15 of the questionnaire 


\section{Validity of the questionnaire}

In the present study, to obtain the necessary validity, the Organ and Kanowski (1996) questionnaire and employees' performance questionnaire were used. The prepared questionnaire was submitted to a number of experts and professors. Given the research hypotheses, some questions were excluded and some of them were added and corrected and the final questionnaire was considered appropriate.

\section{Reliability of the questionnaire}

To calculate the reliability coefficient of the questionnaire as a measurement tool, various methods are used. In this research, Cronbach's alpha method was used. Cronbach's alpha method is used to calculate the internal consistency of measurement tools such as questionnaires.

Table 1 - Calculation of Cronbach's alpha:

\begin{tabular}{|c|c|}
\hline factors & Cronbach's alpha \\
\hline Organizational citizenship behavior & 0.763 \\
\hline Employees' performance & 0.817 \\
\hline
\end{tabular}

In the analysis, alpha was obtained at more than $70 \%$. Thus, the reliability of the questionnaire is acceptable (Calculation details are presented in appendix section).

Method of data analysis

After collecting the required data and information through a questionnaire, all of them were coded and then examined and analyzed using descriptive statistical methods such as mean and inferential statistics including Pearson correlation:

\section{Results}

Table 2- Analyzing age status

\begin{tabular}{ccc}
\hline age & frequency & percentage of frequency \\
\hline younger than 30 years & 2 & 4.6 \\
31-43 years & 10 & 22.7 \\
$41-50$ years & 25 & 56.8 \\
older than 50 years & 7 & 15.9 \\
\hline total & 44 & 100 \\
\hline education & frequency & percentage of frequency \\
\hline diploma and below & - & 79.5 \\
bachelor & 35 & 20.5 \\
\hline master and higher & 9 & 100 \\
\hline total & 44 &
\end{tabular}

As shown in Table 2, out of 44 people, $23 \%$ are under 30 years old, $57 \%$ are 31 to 40 years old, $16 \%$ are 41 to 50 years old and $4 \%$ are over 50 years old. Also, out of 44 samples, $79 \%$ have a bachelor degree and $21 \%$ have a master degree or higher.

Descriptive Statistics:

Table (3). Descriptive statistics related to organizational citizenship behavior and performance variables

\begin{tabular}{|l|l|l|l|l|l|l|}
\hline & $\mathrm{n}$ & mean & $\mathrm{SD}$ & coefficient of variations & $\min$ & $\max$ \\
\hline $\begin{array}{l}\text { Organizational } \\
\text { citizenship behavior }\end{array}$ & 44 & 3.6765 & 0.46006 & 0.1251 & 1.00 & 5.00 \\
\hline Performance & 44 & 3.8460 & 0.32982 & 0.0857 & 3.00 & 4.00 \\
\hline
\end{tabular}

Source: research findings 
Table 3 shows number, mean, standard deviation, coefficient of variation, minimum and maximum in the variable of organizational citizenship behavior and performance. Since the coefficient of variation of organizational citizenship behavior (0.1251) is less than 0.5 , the data are slightly scattered. Thus, the views of the respondents are close to each other and have high agreement. It means that the respondents' beliefs on the role of variable of organizational citizenship behavior on the performance of the statistical population are almost the same and their answers are close to each other.

Also, since the coefficient of variation of the performance variable $(0.0857)$ is less than 0.5 , the data are slightly scattered. Thus, the views of the respondents are close to each other and have high agreement. It means that the respondents' beliefs about the role of performance variable on the performance of the statistical population of the study are almost the same and their answers are close to each other.

\section{Testing the normality of data}

Table 4 - Kolomogorov-Smirnov test

\begin{tabular}{|c|c|c|}
\hline variables & $\mathrm{p}$-value & test result \\
\hline Organizational citizenship behavior & 0.996 & normal \\
\hline Performance & 0.451 & normal \\
\hline
\end{tabular}

According to Table 4 in most research variables ( $\mathrm{Sig}>0.05)$, we conclude that the research variables are normal. Testing the hypothesis

Null hypothesis: There is no significant relationship between organizational citizenship behaviors and employees' performance

Hypothesis 1: There is a significant relationship between organizational citizenship behaviors and employees' performance
$\rho=0$
$H_{O}:$
$\rho \neq 0 \quad H_{1}:$

Table 5- testing the research hypothesis

\begin{tabular}{ccccc}
\hline variables & $\begin{array}{c}\text { number of } \\
\text { respondents }\end{array}$ & $\begin{array}{c}\text { Pearson } \\
\text { coefficient }\end{array}$ & $\alpha$ & p-value \\
\hline $\begin{array}{c}\text { organizational citizenship behaviors and } \\
\text { employees' performance }\end{array}$ & 44 & 760.0 & 05.0 & 000.0 \\
\hline
\end{tabular}

\begin{tabular}{|cc|c|c|}
\hline \multicolumn{4}{|c|}{ Correlations } \\
\hline & Pearson Correlation & $\begin{array}{c}\text { organizational citizenship } \\
\text { behaviors }\end{array}$ & performance \\
\hline & Sig. (2-tailed) & 1 & $.760^{* *}$ \\
$\begin{array}{c}\text { organizational } \\
\text { citizenship } \\
\text { behaviors }\end{array}$ & $\mathrm{N}$ & 44 & .000 \\
\hline $\begin{array}{c}\text { performance } \\
\end{array}$ & Pearson Correlation & $.760^{* *}$ & 44 \\
& Sig. (2-tailed) & .000 & 1 \\
$\mathrm{~N}$ & 44 & 44 \\
\hline
\end{tabular}

**. Correlation is significant at the 0.01 level (2-tailed).

The result obtained from SPSS software shows that the correlation between the two variables of organizational citizenship behaviors and employees' performance is $\mathrm{R}=0.760$, indicating a positive and direct correlation between the two variables and since Sig is $<0.05$, the null hypothesis is rejected and the opposite hypothesis is confirmed. It means that there is a significant and positive relationship between organizational citizenship behaviors and employees' performance (Table 5). 


\section{Conclusion:}

With entry of organizations to service economy, the quality of services has become a challenging issue for them, so that the success of organizations in this economy will depend on high-quality services and customer-oriented employees. Recent studies have shown that one of the factors affecting the quality of services of organizations and creating a competitive advantage is the civic behaviors in employees, especially those who are in direct interaction with customers (Yazdani et al., 2011, p. 54). The research results revealed a significant relationship between organizational citizenship behaviors and employees' performance. Kolmogorov-Smirnov test was used to investigate the normal distribution of data. Since it was found that the data are distributed normally, Pearson correlation test was used to examine the above-mentioned question.

The analysis shows that the significance level is less than 5\% and the correlation between the two variables of organizational citizenship behaviors and employees' performance is 0.760 , so the null hypothesis is rejected and with $95 \%$ confidence, it can be concluded that there is a significant relationship between organizational citizenship behaviors and employees' performance. Performance is one of the factors related to organizational citizenship behavior, so it is crucial to evaluate the relationship between the dimensions of organizational citizenship behavior and performance. In fact, organizational citizenship behavior has been created to assess those job behaviors that go beyond the expected level of works and are affected by performance and job satisfaction. Therefore, organizational citizenship behavior is designed to assess work behaviors that are likely to be influenced by employees' job attitudes, not behaviors that are influenced by individual abilities, and performance is associated with extra-job behaviors such as organizational citizenship behavior.

The present study aimed at evaluating the relationship between organizational citizenship behaviors and employees' performance. In the present study, the components of organizational citizenship behaviors include altruism, conscientiousness, sportsmanship, civic virtue and courtesy. The results revealed that there is a relationship between organizational citizenship behaviors and employees' performance. There is also a relationship between the components of altruism, conscientiousness, sportsmanship, civic virtue, and courtesy and performance. The results of other researchers are mentioned below.

- Musa Khani et al (2012) showed a significant and direct relationship between the variable of organizational citizenship behaviors and employees' performance. The researcher also showed a direct relationship between organizational citizenship behaviors and employees' performance. The results of the present study are consistent with the results of the study conducted by Musa Khani et al (2012). Hanington (2009) showed no significant relationship between organizational culture and organizational citizenship behavior, but the relationship between organizational citizenship behavior and organizational performance was significant. In his research, the researcher evaluated the relationship between organizational citizenship behavior and payment performance. The results revealed a direct relationship between organizational citizenship behaviors and the performance of Pasargad Insurance Company. The results of the present study are in line with those of the study conducted by Hanington (2009). Chen (2000) indicated a positive and significant relationship between organizational citizenship behavior and individual, unit and organizational performance. Finally, based on the results, future researchers are recommended to investigate the relationship between organizational citizenship behavior and the performance of Pasargad Insurance Company employees in other cities and provinces and compare the results with the results of present study. It is also recommended to examine the relationship between each component of organizational citizenship behavior and performance separately for more detailed analysis.

\section{References}

[1] Sanoobari, M, 2008, Organizational Citizenship Behavior, Police Human Development Bi-Quarterly, Volume 5, Issue 16. pp. 79-99

[2] Zarei Matin, H and Ahmadi, F (2009) The role of the university in the development of organizational citizenship behavior, Journal of Islamic Azad University, Issue 41.

[3] Kwantes, C.T. (2003); "Organizational citizenship and withdrawal behaviors in USAand India", International Journal of Cross Cultural Management, 3 (1), p. 5

[4] Appelbaum,Steven Bartolomucci, Nicolas Beaumier,Erika Boulang- er,Jonathan Corrigan,Rodney Dore, Isabelle Girard,Chrystine Serroni, Carlo"organizational citizenship behav- ior:a case study of culture,leadership and trut"manamement decision Vol.42 No.1,(2004),pp.13-40

[5] Eslami, H and Sayar, A (2007), Organizational Citizenship Behavior, Tadbir Magazine, Issue 187.

[6] Aree, Samuel. (2009), High-Performance Human Resource Practices, Citizenship Behavior, and Organizational Performance: A RelationPerspective, Academy of Management Journal Vol. 50, No. 3, 558-577.

[7] Castro., \& Armario and Ruiz, (2004). "The Influence of EmployeeOrganizational Citizenship Behaviour Customer Layalty", International Journalof Service Industry Management, vol. 15, N.1.

[8] Shaemi, Aand Mahmoudi, S (2008) investigating the relationship between organizational citizenship behavior and performance of organizations, the first national conference on organizational citizenship behavior

[9] Bani Fatemi Kashi, SMR (2007) Performance assessment, Journal of Accountant, Issue 185.

[10] Musa Khani, M. Alwani, SM, Mirzaei, M and Mohammadi, S (2010) Investigating the Relationship between Organizational Citizenship Behavior and Employee Performance, Management Quarterly, Volume 8, Issue 2. 